Discussion Paper No. 16-051

\title{
The Demand for Index-Based Flood Insurance in a High-Income Country
}

Martin Achtnicht and Daniel Osberghaus

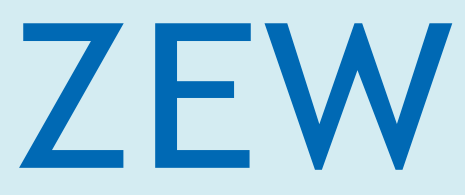

Zentrum für Europäische Wirtschaftsforschung $\mathrm{GmbH}$ Centre for European Economic Research 
Discussion Paper No. 16-051

\title{
The Demand for Index-Based Flood Insurance in a High-Income Country
}

\author{
Martin Achtnicht and Daniel Osberghaus
}

Download this ZEW Discussion Paper from our ftp server:

http://ftp.zew.de/pub/zew-docs/dp/dp16051.pdf

Die Discussion Papers dienen einer möglichst schnellen Verbreitung von neueren Forschungsarbeiten des ZEW. Die Beiträge liegen in alleiniger Verantwortung der Autoren und stellen nicht notwendigerweise die Meinung des ZEW dar.

Discussion Papers are intended to make results of ZEW research promptly available to other economists in order to encourage discussion and suggestions for revisions. The authors are solely responsible for the contents which do not necessarily represent the opinion of the ZEW. 


\title{
The Demand for Index-Based Flood Insurance in a High-Income Country
}

\author{
Martin Achtnicht \\ Leibniz Institute of Ecological Urban and Regional Development (IOER) \\ Weberplatz 1, 01217 Dresden, Germany \\ m.achtnicht@ioer.de \\ Daniel Osberghaus \\ Centre for European Economic Research (ZEW) \\ L7, 1, 68161 Mannheim, Germany \\ osberghaus@zew.de
}

\begin{abstract}
Flood insurance helps to cope with the risk of flooding, but take-up rates are relatively low. Insurance density could rise if index-based insurance (IBI) were provided as an alternative to traditional damage-based insurance (DBI). We analyze whether there is potential for private demand for IBI in Germany. We use data from a discrete choice experiment combined with damage data for a major flood in 2013. We find IBI to attract similar customers as DBI, while DBI is preferred on average. Our results suggest that not many new customers would enter the market, once IBI were available. (JEL Q54, R22)
\end{abstract}

KEYWORDS: Climate Change; Discrete Choice Experiment; Floods; Insurance; Index-based

JEL-CODES: Q54, G22, D14

ACKNOWLEDGEMENTS: The authors thank Sonia Akter, Goytom Abraha Kahsay and Jürgen Meyerhoff for helpful comments and suggestions, and the German Insurance Association (GDV) for providing county data on flood insurance claims. Financial support of the German Ministry for Education and Research (BMBF) under the grant no. 01LA1113C is gratefully acknowledged. The funding source and the GDV had no involvement in study design, analysis and interpretation of the data, writing and publishing of the article. 


\section{INTRODUCTION}

Floods pose a major natural hazard to economic development and human well-being, in developing as well as high-income countries (Ciscar et al. 2011). Moreover, climate change is expected to induce an increase in severity and frequency of flood events (Hirabayashi et al. 2013; IPCC 2012). Against this background, flood insurance plays an important role in coping with floods, mitigation of damage, and pricing of risks. Climate change will only increase the relevance of viable insurance markets. However, take-up rates for private flood insurance are remarkably low (Schwarze et al. 2011). Even if premiums are subsidized, demand often stays behind expectations (Kunreuther 1984). As high insurance levels are generally desired by policy makers, governments try to foster private demand by various instruments, such as public insurance programs (e.g. in the US), publicly financed reinsurance (e.g. in France), or risk awareness campaigns (e.g. in Germany). Despite these efforts, in insurance markets without an obligation to insure flood risks the take-up rates remain relatively low. In Germany, market penetration of flood insurance is as low as 38\%, albeit increasing in the last years (GDV 2015).

In developing countries, index-based insurance (IBI) has been seen as a promising opportunity to enhance private demand for insurance (Skees 2008) and thereby foster adaptation to climate change (Collier et al. 2009). In the case of IBI, payments of the insurer are bound to one or several previously determined weather indices which correlate with damage, e.g. the amount of precipitation at a specific location. Major advantages relative to damage-based insurance (DBI) are lower administrative costs (typically individual damage assessments are not needed) and the absence of moral hazard. However, IBI bears the risk that the actual damage of an insured is not fully covered (this risk is referred to as "base risk").

Although there is substantial experience and research with IBI in developing countries, it is not clear yet whether such insurance could also enhance insurance demand in a high-income country context. This is exactly the topic of this paper. We analyze the demand for conventional (damage-based) and index-based flood insurance in the case of Germany using data from a discrete choice experiment (DCE). We identify factors that influence the choice between damage-based, index-based, and no flood insurance. In particular, by exploring the take-up potential of index-based flood insurance we provide the first empirical results on its attractiveness in a high-income country.

The advantages of IBI relative to DBI are most relevant in developing countries. In particular, on-site damage assessments are often complex and costly in remote, rural areas. With IBI, individual damage assessments become obsolete and administrative costs of the insurance may fall substantially. In some cases, IBI may permit retailing insurance policies where it was not possible with conventional, damages-based policies. This is different in high-income countries. Individual damage assessments are easier and flood insurance markets are typically well developed. But there is a number of arguments why IBI, especially index-based flood insurance, may become more important even in richer countries.

First, given a low insurance penetration of less than $40 \%$, insurance companies may see the opportunity to gain new clients by offering a new, possibly cheaper product type based on weather indices. Especially in a highly competitive insurance market like Germany, the potential of reaching new clients may trigger the interest and efforts of insurance companies in developing an IBI. Furthermore, moral hazard is often seen as a problem for flood insurance as policy holders have some possibilities to influence their own risk ex ante (Skees and Barnett 1999). With IBI, insurance coverage does not reduce the incentives to mitigate flood risk - hence there is no risk of moral hazard. Also, policymakers have an interest that 
more households insure themselves and may see IBI as an additional instrument to reach higher take-up rates. This finds expression in the EU's green paper on insurance (European Commission 2013, p.10), which says that "(IBI) can improve affordability of insurance by reducing administrative costs, because it does not include a claims adjustment process. It also speeds up pay-outs, and can be associated with simpler insurance contracts.”

Second, there is already a small, but increasing market of various IBI for consumers also in high-income countries. In Germany, clients can insure against rainy weather during their summer holiday or when visiting outdoor fun parks. Businesses, e.g. outdoor caterer or event manager, can insure against income losses due to bad weather. These policies are partly seen as oddities so far, but may get more relevant in future.

Finally, in high-income countries accurate and reliable weather observations are typically well available - this is a precondition for the functioning of IBI schemes. Regarding flood insurance, possible indices may include precipitation which is observed via radar systems and weather stations. The extent of river flooding can be assessed by automatic gauges and satellites. In Germany, which we take as a case study, all these weather observation systems are well available and provide a spatially and temporally detailed and accurate picture of hydrological events such as floods. Moreover, high-income countries are typically in the position to provide long term and reliable weather data, which would be needed for setting the parameters of an IBI scheme. In this context, the German Insurance Association (GDV) recently started a research project on the correlation of heavy rain and insured damage in the 2000s (GDV 2015). Potentially, the results may be used for parametrizing an index-based flood insurance and assessing the base risk which stays with the insured household.

Hence, we see very good technical and scientific preconditions for IBI schemes in highincome countries like Germany. At the same time, policymakers on the national and European level have expressed their objective of fostering private flood insurance demand. With the potential to gain new clients in a highly competitive market while avoiding the moral hazard problem, we conclude that index-based flood insurance may be developed and marketed also in high-income countries in future. Our research enables first insights into the extent and determinants of demand for this innovative product.

The remainder of the paper is structured as follows. In lack of existing literature on the demand for index-based flood insurance in high-income countries, we review two related literature strands in Section 2: empirical studies focusing on demand for IBI in developing countries, and those analyzing conventional flood insurance markets in high-income countries. In Section 3, we describe the data, the experimental design, and the econometric approach used in our analysis. The empirical results are presented and discussed in Section 4. The final section summarizes and concludes.

\section{LITERATURE REVIEW}

In this section, we first review the empirical literature on IBI demand in developing countries. For high-income countries, there is almost no empirical evidence. However, in order to relate our results to the existing literature, we will summarize the main determinants of conventional flood insurance demand in Germany and other high-income countries in the second part of this section.

There is a growing literature body on the determinants of IBI in developing countries (see Miranda and Farrin [2012] for a literature review on case studies throughout the world). So 
far, all implemented or hypothetical insurance schemes which were analyzed empirically provide coverage of agricultural or pastoral production. Hill et al. (2013) use Ethiopian rural household survey data and show that educated, wealthy, and risk-seeking households are more likely to purchase IBI. These results are broadly confirmed by Bogale (2015) who finds additional negative effects of the availability of non-farm income and remittances. Giné et al. (2008) report similar results for smallholder farmers in rural India. Alongside household and farm characteristics, results of Cole et al. (2014) suggest that experience in the village may play a major role. By using panel data of seven years in an Indian context, they find that the probability to purchase index-based crop insurance increases with previous payouts within the same village. The authors conclude that information about insurance payouts have villagewide demand effects. Regarding the role of product comprehension, Takahashi et al. (2016) come to the conclusion that improved knowledge about IBI per se does not necessarily increase demand. However, they find strong evidence for price effects in their data from Ethiopia. Finally, gender differences in the demand for IBI are analyzed by Akter et al. (2016). The results from a DCE in coastal Bangladesh suggest that women are less willing to use insurance services, which cannot be fully explained by differences in risk and time preferences. Instead, farmers' level of trust in the insurance industry and financial literacy are suggested as the main determinants of gender differences in the preferences for IBI.

For index-based agricultural insurance demand in high-income countries, there is very limited evidence. In a DCE on government intervention in agricultural insurance markets in Finland, Liesivaara and Myyrä (2014) postulate a higher willingness-to-pay for index-based contracts than for comparable conventional insurance policies. Being a by-product in their paper, the authors do not further discuss this result. To the best of our knowledge, there is no single study on the demand for IBI covering private homes or contents. However, we can draw on a large and growing number of empirical studies on demand for conventional (damage-based) flood insurance in high-income countries. Most of these studies use household survey data to assess the demand for insurance coverage. Exceptions are Browne et al. (2015), who exploit customer data of a large insurance company in Germany, and Browne and Hoyt (2000) and Kriesel and Landry (2004), who analyze the extent of flood insurance demand on a larger regional level (states or communities, respectively). In terms of methodology, Botzen and van den Bergh (2012) and Brouwer and Schaafsma (2012) are very close to our approach. Both studies employ DCEs in order to assess the demand for an insurance product which is not available in the market. Both focus on insurance demand in the Netherlands. For Germany, flood insurance demand has been analyzed in a small number of studies (Browne et al. 2015; Bubeck et al. 2013; Raschky et al. 2013). The remaining literature on flood insurance demand covers countries like the USA (Landry and Jahan-Parvar 2011; Lindell and Hwang 2008; Petrolia et al. 2013), the Netherlands (Terpstra and Lindell 2012), and the UK (Bichard and Kazmierczak 2012). Most of these studies show that the attractiveness of flood insurance correlates positively with income, the value of the home, household size, perceived flood risk, and prior damage experience. Throughout all studies, demand correlates negatively with insurance premiums, often with a lower sensitivity for higher income households. Further control variables (e.g. gender, age, level of education) show mixed or non-significant correlations with insurance demand.

Our contribution to the existing literature is the following: We provide novel empirical evidence on the demand for index-based insurance outside the agriculture and livestock sector and in a high-income country context. Furthermore, we compare preferences for conventional and index-based flood insurance, and quantify the differences in utility between the two in monetary terms. 


\section{DATA AND METHODS}

\subsection{Data and Experimental Design}

We use data from a DCE in which respondents could choose between damage-based and index-based flood insurance, and no flood insurance. The DCE was part of a larger survey of German homeowners conducted in June and July 2014 by forsa, a professional market research company. ${ }^{1}$ Some 4,000 homeowners were sampled from forsa's master household sample, which is nationally representative of household size and regional distribution. The questionnaire was accessible online and via the TV screen at home. Respondents were queried about their beliefs, experiences, perceptions, and attitudes on various issues related to extreme weather events and climate change adaptation. During the survey period no natural disaster occurred in Germany or was prevalent in the media. The most recent major flood in Germany occurred in June 2013, one year before the survey, which may have had an effect on flood risk perception, especially in the affected regions (e.g., Atreya et al. 2013; Kousky 2010). In order to be able to control for the effects of the 2013 flood on insurance demand, we merge the survey data with data on flood insurance claims provided by the GDV.

From the sampled homeowners, 3,465 live in a detached house or use ground floors or basements and are thus potentially interested in insuring their property against floods. Since respondents were expected to be unfamiliar with index-based insurance, they were informed about its characteristics prior to the DCE. A concise paragraph explained that the insurer's payment is then based on a predetermined weather index, such as rainfall or water level, and independent from the actual damage, emphasizing that in some cases the payment may be higher than the damage while in others lower. This paragraph was followed by the question whether the respondent would generally consider such an index-based flood insurance, if available. Only those who did not categorically rule out IBI at this stage (35\%) were presented with the DCE. This was done because of our concern that people who are unresponsive to index-based insurance might not seriously participate in the DCE, leading to biased coefficient estimates. Therefore, the final sample of this study consists of 1,161 homeowners. $^{2}$

We kept the experimental design very simple. The DCE involved two labelled insurance alternatives, one damage-based and one index-based, both described by only one attribute, the insurance premium. Respondents were instructed to consider the alternatives to be identical in all other respects (e.g., insurance company, sales channel) and asked to select the most preferred one. In order to enhance the realism of the choice setting (Carson et al., 1994), respondents also had the option to opt out by choosing no flood insurance at zero costs. Figure 1 shows an example of a choice set (translated from German).

\footnotetext{
${ }^{1}$ For more information on the survey, including the questionnaire (in German language), see Osberghaus (2015).

${ }^{2}$ Differences between the original and final sample are presented in Section 4. Note that 46 respondents who did not rule out IBI abandoned the survey before answering the DCE.
} 
Figure 1: Example choice set

Which policy would you prefer for insuring your home against flood damage?

\begin{tabular}{|c|c|c|c|}
\hline Type of insurance & $\begin{array}{c}\text { Normal insurance, i.e. } \\
\text { payout depends on } \\
\text { damage }\end{array}$ & $\begin{array}{c}\text { Weather-based insurance, } \\
\text { i.e. payout depends on } \\
\text { weather }\end{array}$ & No flood insurance \\
\hline Premium & $\begin{array}{c}40 \\
\text { Euros per year }\end{array}$ & Euros per year & 0 \\
Euro
\end{tabular}

For the insurance premium, we used three attribute levels when designing the choice sets: low, medium, and high. When answering the choice sets, respondents saw premium levels in euro-per-year terms, which were customized based on the respondent's perceived flood risk at home. The perceived flood risk was queried earlier in the questionnaire using the four risk categories used by the GDV. Table 1 shows these risk categories, the share of respondents, and the related premium levels. The selected attribute levels reflect current prices for flood insurance and the fact that premiums increase with risk. They were drawn from Stiftung Warentest, the leading German consumer organization, and FinanceScout24, a pricecomparison website for financial products. By customizing the insurance premium that way, we enhance the relevance of the attribute levels (Hensher et al., 2005) and make the choice sets more realistic.

Table 1: Flood risk categories and premium levels in the discrete choice experiment

\begin{tabular}{lrrrr}
\hline & & \multicolumn{2}{c}{ Premium level (€/year) } \\
\cline { 3 - 5 } Flood risk (statistical recurrence interval of flooding) & Resp. (\%) & Low & Medium & High \\
\hline At least once every 10 years & 16.9 & 400 & 1,200 & 2,400 \\
Once every 10 to 50 years & 18.4 & 80 & 200 & 400 \\
Once every 50 to 200 years & 16.3 & 40 & 70 & 120 \\
More rarely than once every 200 years & 34.1 & 20 & 50 & 80 \\
Don't know & 14.3 & 40 & 70 & 120 \\
\hline
\end{tabular}

Given two labelled alternatives and one three-level attribute, there are only nine $\left(3^{(2 \times 1)}\right)$ possible choice sets. However, we further reduced this number to six by dropping those choice sets where the two insurance alternatives are equally priced, while keeping the design orthogonal and level balanced. In the DCE, each respondent faced these same six choice sets, but in randomized order and, as mentioned above, with customized premium levels.

Before answering the series of choice tasks, respondents were provided with a set of instructions. First, we have to consider that we do not know the real status quo of their insurance coverage. ${ }^{3}$ Hence, respondents were asked to answer as if they have no flood insurance on their home yet. Therefore, whenever respondents opt out and choose no flood insurance, we do not have to worry about anyone interpreting this option as falling back to any own insurance cover, for which we lack credible information. Second, respondents were reminded of their self-reported perceived flood risk and asked to consider this risk level in their choice. Respondents who answered “don’t know” to the risk question were told to

\footnotetext{
${ }^{3}$ Although the homeowners reported their flood insurance coverage, the answers showed that many participants were uncertain. Comparisons with insurance penetration data of the GDV suggest that many homeowners may overestimate their own insurance coverage (Osberghaus 2015).
} 
consider a flood risk of once every 50 to 200 years. Third, respondents were asked to assume that the thresholds of rainfall and water level used for the index-based alternative are chosen such that, on average, its insurance payments equal that of the damage-based alternative (though it can be lower or higher than the actual damage in a specific case). And finally, they were told to assume that rainfall and water level can be measured accurately and reliably for their property, for example by satellite technology.

\subsection{Econometric Modelling}

We assume a random utility framework to analyze the choice data, as is typically done in DCE studies. In this framework, the utility $U_{n j t}$ provided by alternative $j$ to person $n$ in choice situation $t$ is assumed to be

$$
U_{n j t}=V_{n j t}+\varepsilon_{n j t}
$$

where $V_{n j t}=V\left(\mathbf{x}_{n j t}\right)$ is a deterministic (observed) utility component, depending on attributes of the alternative and characteristics of the person $\mathbf{x}_{n j t}$, and $\varepsilon_{n j t}$ is a (unobserved) stochastic component. According to the economic theory of utility-maximising behaviour, person $n$ chooses that alternative from the alternative set $\{1, \ldots, J\}$ which provides him with the greatest utility. Since utility is modeled as a random variable, however, only choice probabilities can be estimated. Depending on the assumptions made about the distribution of the random variables $\varepsilon_{n j t}(n=1, \ldots, N ; j=1, \ldots, J ; t=1, \ldots, T)$, different classes of discrete choice models can be defined.

In this paper, we use both standard multinomial logit (MNL) and mixed logit (MXL) models for the analysis. In MNL models, the $\varepsilon_{n j t}$ are independent and identically distributed (iid) with type 1 extreme value distribution. As we further assume $V$ to be linear in unknown parameters $\boldsymbol{\beta}$, the probability that person $n$ chooses alternative $i$ in choice situation $t$ takes the following closed form (e.g., Train 2009):

$$
P_{n i t}=\frac{\exp \left(\boldsymbol{\beta}^{\prime} \mathbf{x}_{n i t}\right)}{\sum_{j=1}^{J} \exp \left(\boldsymbol{\beta}^{\prime} \mathbf{x}_{n j t}\right)}
$$

In our case, there are three alternatives per choice set $(J=3)$ : a damage-based flood insurance $(j=1)$, an index-based flood insurance $(j=2)$, and no flood insurance $(j=3)$. The no insurance alternative is used as the base alternative, its deterministic utility $V_{n 3 t}$ is therefore normalized to zero.

In the MXL specification, we include an additional error component $\eta_{n} d_{n j t}$, where $\eta_{n}$ is a normally distributed random term with zero mean, and $d_{n j t}$ a dummy variable that identifies the two flood insurance alternatives (i.e. $d_{n j t}=1$ if $j<3$; 0 otherwise). Thereby, we allow the two insurance types to be correlated in unobserved factors. This relaxes the well-known IIA assumption of standard logit, and thus might represent a more realistic substitution pattern, in particular in the presence of the no insurance alternative (e.g., Scarpa et al. 2005; Hess and Rose 2009). In addition, we specify the insurance premium coefficient $\alpha$ to be lognormally distributed. This allows for unobserved heterogeneity in price sensitivity while ensuring the behaviourally plausible coefficient sign and finite moments for willingness-topay estimates (e.g., Daly et al. 2012). To account for repeated choices by the same person, we hold these two random terms constant over choice situations. The probability for a sequence of choices $\mathbf{i}=\left(i_{1}, \ldots, i_{T}\right)$ can then be written as the double integral of a product of standard 
logit probabilities over all values of $\alpha$ and $\eta$, weighted by the (normal) density $f$ of $\ln (\alpha)$ and the (normal) density $g$ of $\eta$ (e.g., Train 2009), i.e.

$$
P_{n \mathbf{i}}=\iint \prod_{t=1}^{T} \frac{\exp \left(\alpha p_{n i_{t} t}+\boldsymbol{\beta}^{\prime} \mathbf{x}_{n i_{t} t}+\eta d_{n i_{t} t}\right)}{\sum_{j=1}^{J} \exp \left(\alpha p_{n j t}+\boldsymbol{\beta}^{\prime} \mathbf{x}_{n j t}+\eta d_{n j t}\right)} f\left(\ln (\alpha) \mid \mu_{\alpha}, \sigma_{\alpha}\right) g\left(\eta \mid 0, \sigma_{\eta}\right) d \alpha d \eta
$$

where $\boldsymbol{\beta}, \mu_{\alpha}, \sigma_{\alpha}$ and $\sigma_{\eta}$ are the parameters to be estimated. As this double integral cannot be solved analytically, it has to be approximated through simulation during the estimation process. We use Halton draws with 2,500 replications for the maximum simulated likelihood estimation.

Table 2 describes the variables used in the econometric analysis. We regress the choice outcome on insurance premium, type of insurance as well as individual and property characteristics. We include information on the respondent's gender, age, education, risk attitude, and perceived flood risk as well as the household's income. In addition, we control for the house value, implemented flood protection measures, and damage caused by the 2013 flood in the respective county. Because the non-experimental variables do not vary over alternatives, they enter the choice models interacted with alternative-specific dummy variables for damage-based and index-based flood insurance. In this way, we can identify who is more likely to choose a particular insurance type.

Table 2: Variables and summary statistics

\begin{tabular}{|c|c|c|c|c|c|c|}
\hline Variable name & Definition & Mean & SD & Min. & Max. & Obs. \\
\hline Insurance & $\begin{array}{l}1 \text { if alternative is damage-based or index- } \\
\text { based insurance }\end{array}$ & 0.67 & 0.47 & 0 & 1 & - \\
\hline Insurance premium & Annual insurance premium in $€ 1,000$ & 0.20 & 0.49 & 0 & 2.40 & - \\
\hline Woman & 1 if respondent is female & 0.30 & 0.46 & 0 & 1 & 1,161 \\
\hline Age & Respondent's age in years & 56.09 & 11.60 & 20 & 85 & 1,160 \\
\hline University & $\begin{array}{l}1 \text { if respondent received a university } \\
\text { degree }\end{array}$ & 0.31 & 0.46 & 0 & 1 & 1,146 \\
\hline Income & $\begin{array}{l}\text { Household's monthly net income in } \\
€ 1,000 \text { (midpoints of } 12 \text { income } \\
\text { categories) }\end{array}$ & 3.32 & 1.33 & 0.25 & 5.75 & 991 \\
\hline Risk attitude & $\begin{array}{l}\text { Self-reported risk attitude on a scale from } \\
0 \text { (not at all risk taking) to } 10 \text { (very risk } \\
\text { taking) }\end{array}$ & 4.82 & 2.00 & 0 & 10 & 1,161 \\
\hline House value & $\begin{array}{l}\text { Self-reported new construction value of } \\
\text { the property in } € 100,000\end{array}$ & 2.86 & 4.37 & 0.10 & 120 & 847 \\
\hline Flood protection & $\begin{array}{l}1 \text { if respondent implemented flood } \\
\text { protection measures to his/her home }\end{array}$ & 0.53 & 0.50 & 0 & 1 & 1,071 \\
\hline Flood of 2013 & $\begin{array}{l}\text { Share of flood insurance claims at county } \\
\text { level during the } 2013 \text { flood in per cent }\end{array}$ & 0.89 & 1.63 & 0.04 & 12.52 & 1,161 \\
\hline Flood risk $>10$ years & $\begin{array}{l}1 \text { if respondent perceives a flood risk of } \\
\text { at least once every } 10 \text { years }\end{array}$ & 0.17 & 0.37 & 0 & 1 & 1,161 \\
\hline Flood risk $10-50$ years & $\begin{array}{l}1 \text { if respondent perceives a flood risk of } \\
\text { once every } 10 \text { to } 50 \text { years }\end{array}$ & 0.18 & 0.39 & 0 & 1 & 1,161 \\
\hline $\begin{array}{l}\text { Flood risk 50-200 } \\
\text { years }\end{array}$ & $\begin{array}{l}1 \text { if respondent perceives a flood risk of } \\
\text { once every } 50 \text { to } 200 \text { years }\end{array}$ & 0.16 & 0.37 & 0 & 1 & 1,161 \\
\hline Don’t know flood risk & $\begin{array}{l}1 \text { if respondent answered “don’t know” } \\
\text { to the flood risk question a }\end{array}$ & 0.14 & 0.35 & 0 & 1 & 1,161 \\
\hline
\end{tabular}


The insurance premium enables us to measure differences in utility between the insurance alternatives in monetary terms. The extra premium that keeps utility constant when switching from alternative $j$ to alternative $i$ is given by the following ratio:

$$
p^{\text {extra }}=-\frac{V_{i}-V_{j}}{\alpha}
$$

Since $\alpha$ is lognormally distributed and the numerator is constant, $p^{\text {extra }}$ also follows a lognormal distribution. If $p^{\text {extra }}$ is positive, it can be interpreted as the willingness to pay (WTP) for switching from $j$ to $i$, otherwise as the compensation that leaves the insured not worse off.

\section{RESULTS}

There is widespread skepticism in our sample about the benefits of IBI. ${ }^{4}$ Almost two-thirds of homeowners stated that they would not consider IBI to protect their property, even if it were cheaper than a conventional DBI. The remaining would possibly consider it (22\%) or were undecided (13\%). Recall that only the latter two groups of respondents, those who did not categorically rule out the IBI option, were presented with the DCE. Contingency table and simple logit regression analysis reveals that those perceiving higher flood risks and having implemented flood protection measures are more likely to judge IBI favorably. We find that women tend to be more undecided. But there are no significant differences in terms of age, education, income, risk attitudes, or actual insurance coverage between the sceptics and the rest. Detailed results for this analysis are not reported here but are available upon request.

In the DCE, with varying insurance premiums, the IBI alternative was chosen in $22 \%$ of the cases, DBI in $42 \%$, and no flood insurance in 36\%. Interestingly, $23 \%$ of the chosen IBI alternatives were more expensive than their DBI counterparts. We are interested in identifying the factors that influence homeowners to choose one flood insurance over another. Therefore, as mentioned above, we regress the choice outcome on insurance premium, type of insurance, and individual-specific factors, using MNL and MXL model specifications. The next section presents and discusses the parameter estimates.

\subsection{Parameter Estimates}

Table 3 shows the results of our multivariate regression analysis of the choice data. The first two columns give the estimates of the MNL model that provides a useful starting point for our empirical analysis. Let us look at the two main findings that emerge from MNL, and which are consistent with those from MXL.

\footnotetext{
${ }^{4}$ In the remainder of the paper, the abbreviations IBI and DBI refer specifically to index-based flood insurance and damage-based flood insurance, respectively.
} 
Table 3: Multinomial and mixed logit models of flood insurance choices

\begin{tabular}{|c|c|c|c|c|}
\hline & \multicolumn{2}{|l|}{ MNL } & \multicolumn{2}{|l|}{ MXL } \\
\hline & Coef. & Std. Err. & Coef. & Std. Err. \\
\hline Insurance premium & $-1.158 * * *$ & 0.084 & $1.834 * * *$ & 0.136 \\
\hline $\begin{array}{l}\text { Damage-based } \\
\text { Woman } \\
\text { Age } \\
\text { University } \\
\text { Income } \\
\text { Risk attitude } \\
\text { House value } \\
\text { Flood protection } \\
\text { Flood of } 2013 \\
\text { Flood risk > } 10 \text { years } \\
\text { Flood risk 10-50 years } \\
\text { Flood risk 50-200 years } \\
\text { Don't know flood risk } \\
\text { ASC }\end{array}$ & $\begin{array}{l}0.422 * * * \\
-0.004 \\
-0.250^{* * *} \\
0.067 * * \\
0.061 * * * \\
0.029 \\
0.380^{* * *} \\
0.038 \\
1.874 * * * \\
1.546^{* * *} \\
1.194^{* * *} \\
0.986^{* * *} \\
-0.837 * * *\end{array}$ & $\begin{array}{l}0.091 \\
0.004 \\
0.085 \\
0.031 \\
0.019 \\
0.020 \\
0.076 \\
0.024 \\
0.146 \\
0.114 \\
0.112 \\
0.125 \\
0.246\end{array}$ & $\begin{array}{l}1.537 * \\
-0.082^{* *} \\
-0.387 \\
0.206 \\
0.147 \\
0.137 \\
1.491^{* *} \\
0.240 \\
6.488^{* * *} \\
8.229^{* * *} \\
6.306^{* * *} \\
5.434^{* * *} \\
3.500\end{array}$ & $\begin{array}{l}0.792 \\
0.032 \\
0.747 \\
0.277 \\
0.174 \\
0.303 \\
0.689 \\
0.241 \\
1.074 \\
1.081 \\
1.017 \\
1.269 \\
2.216\end{array}$ \\
\hline $\begin{array}{l}\text { Index-based } \\
\text { Woman } \\
\text { Age } \\
\text { University } \\
\text { Income } \\
\text { Risk attitude } \\
\text { House value } \\
\text { Flood protection } \\
\text { Flood of } 2013 \\
\text { Flood risk > } 10 \text { years } \\
\text { Flood risk 10-50 years } \\
\text { Flood risk 50-200 years } \\
\text { Don’t know flood risk } \\
\text { ASC }\end{array}$ & $\begin{array}{l}0.380 * * * \\
-0.009 * * \\
-0.094 \\
0.024 \\
0.087 * * * \\
0.033 \\
0.401 * * * \\
0.087 * * * \\
2.171^{* * *} \\
1.613^{* * *} \\
1.320^{* * *} \\
0.568 * * * \\
-1.287 * * *\end{array}$ & $\begin{array}{l}0.103 \\
0.004 \\
0.097 \\
0.036 \\
0.022 \\
0.020 \\
0.088 \\
0.026 \\
0.149 \\
0.128 \\
0.127 \\
0.158 \\
0.281\end{array}$ & $\begin{array}{l}1.490^{*} \\
-0.086^{* * *} \\
-0.220 \\
0.176 \\
0.176 \\
0.145 \\
1.524 * * \\
0.303 \\
6.804^{* * *} \\
8.018^{* * *} \\
6.386^{* * *} \\
4.809^{* * *} \\
2.836\end{array}$ & $\begin{array}{l}0.790 \\
0.032 \\
0.744 \\
0.276 \\
0.174 \\
0.303 \\
0.687 \\
0.241 \\
1.073 \\
1.075 \\
1.014 \\
1.261 \\
2.207\end{array}$ \\
\hline $\begin{array}{l}\text { S.D. of random parameter } \\
\text { Insurance premium }\end{array}$ & & & $2.454^{* * *}$ & 0.117 \\
\hline $\begin{array}{l}\text { S.D. of error component } \\
\text { Insurance }\end{array}$ & & & $6.088 * * *$ & 0.486 \\
\hline $\begin{array}{l}\text { Individuals } \\
\text { Observed choices } \\
\text { Log likelihood } \\
\text { AIC } \\
\text { Pseudo } R^{2}\end{array}$ & $\begin{array}{l}732 \\
4,392 \\
-4361.9 \\
8777.7 \\
0.096\end{array}$ & & $\begin{array}{l}732 \\
4,392 \\
-2963.2 \\
5984.4 \\
0.386\end{array}$ & \\
\hline
\end{tabular}

Notes: Column 3 gives the estimated mean $(\mu)$ and standard deviation $(\sigma)$ of the log of the insurance premium coefficient (with the negative of insurance premium entering the MXL model); the median, mean, and standard deviation of the coefficient itself can be computed by $\exp (\mu), \exp \left(\mu+\sigma^{2} / 2\right)$, and $\exp \left(\mu+\sigma^{2} / 2\right) \times$ $\sqrt{\exp \left(\sigma^{2}\right)-1}$, respectively (Hole 2007). Triple, double, and single asterisks denote statistical significance at the $1 \%, 5 \%$, and $10 \%$ levels, respectively.

First, we find the insurance premium and the self-perceived flood risk to be the two most important factors in choosing a flood insurance, regardless of the type. Higher premiums make flood insurance less attractive, higher flood risks make them more attractive, as expected. This is consistent with results from previous studies (e.g., Kunreuther 1996; Browne and Hoyt 2000; Botzen and van den Bergh 2012; Brouwer and Schaafsma 2013). For each flood risk category (see Table 1), a single dummy variable is included in the model, with 
the lowest risk - a recurrence interval of at least 200 years - serving as the omitted category. All these risk dummies enter positively and significantly; the point estimates of their coefficients even increase monotonically with perceived flood risk (which is not quite the case in the MXL model). With a further dummy, we separately identify respondents who answered "don't know" to the flood risk question. Those were asked to consider a flood risk of once every 50 to 200 years when answering the DCE. The estimated coefficients for the "don't know" variables are positive and significant, too, but lower than the other ones, suggesting that perceived risks influence choices stronger than assumed risks.

Second, we find the alternative-specific coefficient estimates to be equal in sign and very similar in magnitude for DBI and IBI. We include a number of covariates that are invariant across alternatives, such as age, income, or house value, to control for observed heterogeneity of preferences. Some of them appear to influence choices, some do not, as we will discuss later. However, the impact of most of these variables does not significantly differ between the two types of insurance policies. So these variables affect, if at all, the choice of any flood insurance over the non-option, but not so much the choice between DBI and IBI. Statistically significant differences between DBI and IBI can be observed only in terms of experiences with Germany's 2013 flood, the highest flood risk level (i.e., recurrence interval of 10 years or less), and to a lesser extent education. ${ }^{5}$ Homeowners living in 2013 flood-hit counties or who perceive an extremely high level of flood risk tend to prefer IBI over DBI (Wald tests: $p=0.027$ and $p=0.028$, respectively). This suggests that once people see themselves confronted with the threat of flooding, be it implied or expressed, the simpler and less bureaucratic IBI becomes more attractive. It is possible that some of these homeowners or their neighbors experienced flood damage in the past and were dissatisfied with the performance of their insurer, and therefore prefer IBI. It is also possible, however, that IBI is perceived as a way to profit from future flood events in these high-risk areas. Whenever one's own damage is expected to be smaller than payouts, IBI is a good choice. Lastly, individuals with a university degree seem to be more reluctant to take up damage-based flood insurance, but not so much index-based ones (Wald test: $p=0.082$ ).

Let us now turn to the estimated MXL model shown in the last two columns of Table 3 . The MXL model clearly outperforms the MNL model. Allowing for random price sensitivity as well as correlation in unobserved factors and over time improves the model fit considerably (likelihood ratio test: $p=0.000$ ).

The error component itself enters the choice model highly significantly, indicating correlation in the unobserved portion of utility between the two insurance alternatives. This leads to increased substitution between DBI and IBI. In other words, a cheaper IBI would attract disproportionately more homeowners who previously have selected the damage-based alternative than those who have opted for no flood insurance at all, and vice versa. This possibility was ruled out in the MNL specification.

Likewise, the standard deviation of the log of the random insurance premium coefficient is highly significant. This indicates strong heterogeneity in price sensitivity among homeowners, which was not accounted for in the MNL model. The positive sign of the mean estimate of the $\log$ of the insurance premium coefficient does not mean that homeowners prefer higher premiums, the opposite is true. Because the natural logarithm is defined only for positive

\footnotetext{
${ }^{5}$ There is also a statistically significant difference for respondents who did not know how to rate their property's flood risk, preferring DBI over IBI. Possibly, those who are too "lazy" to think about probabilities of flood events also tend to be unwilling to consider and become familiar with the unfamiliar insurance alternative, but this is only speculation.
} 
numbers and insurance premium is expected to have a negative coefficient, we follow the standard procedure and let the negative of insurance premium enter the MXL model (e.g., Hensher and Greene 2003; Hole 2007; Train 2009). A positive coefficient of negative premiums implies that utility decreases with increasing premiums.

Otherwise, the MXL model basically confirms the results of the MNL model, although the magnitude of the estimated coefficients increases and the significance level of some of them changes. The former effect is simply due to the different scale of utility, as now some of the variance in the unobserved factors is captured by the additional random terms instead of the iid $\varepsilon$, whose normalization determines the scale (Brownstone and Train 1999).

In contrast to findings from the Netherlands (Botzen and van den Bergh 2012), we find women to be more likely to select a flood insurance policy. The age coefficients for both flood insurance types are negative and significant. On average, older homeowners are wealthier, more likely to have paid off their mortgage, and less likely to experience a flood in their remaining lifetime. All of these factors might make them less concerned about possible flood damage and might explain our finding. The effect of income and house value on insurance demand is positive but not significant. Somewhat counterintuitively, the risk attitude variables have positive coefficients. Although the estimates lose their significance in the MXL model, the positive signs are robust to alternative specifications that we have tried. One explanation could be that risk-taking people tend to buy homes at higher flood risk, and that the risk characteristics of the property site are not fully captured by the other covariates. On the other hand, it is possible that our relatively simple measure for risk attitude is too imprecise to reflect the different types of risk-taking behavior documented in the literature (Bruhin et al. 2010; Petrolia et al. 2013). Homeowners who have implemented measures to protect their property from flooding and to limit the damage are more likely to select a flood insurance. Flood protection measures we observed include backflow traps, water-repellent rendering, water-resistant floors such as stone and tiles, but also non-technical measures such as moving valuable furnishings to the upper floors. Thus, we find no evidence for adverse selection in the sense that, conditional on having the same level of flood risk, the more vulnerable and unprepared have a higher demand for flood insurance. Rather, it seems that (arguably risk-averse) homeowners regard flood protection and insurance as complements. Our finding on private flood protection seems consistent with the empirical evidence on community- or state-level flood protection (Kriesel and Landry 2004; Botzen and van den Bergh 2012), although its effect on insurance demand varies across the types of measures (Landry and Jahan-Parvar 2011), across regions (Petrolia et al. 2013), and is sometimes an artefact of country-specific market conditions (Bubeck et al. 2013).

Remember that the effect of all these variables does not vary significantly between DBI and IBI. This shows that IBI attracts similar customers as DBI. Nevertheless, we find strong evidence that homeowners, on average, prefer DBI to IBI. This is indicated by the significant difference between the two alternative-specific constants (ASCs), which capture the average effects of omitted factors on utility (Wald test: $p=0.041$ ). In the next section, we will quantify the difference in utility between DBI and IBI in monetary terms.

\subsection{Willingness to Pay}

Based on the MXL model, we derive the WTP for having one's property flood insured with a DBI instead of an IBI. The WTP is the difference in premiums between DBI and IBI that keeps utility constant when changing the type of insurance. It is the extra premium people would pay to avoid the base risk inherent to IBI. As described in Section 3.2, the WTP follows a lognormal distribution. Lognormal distributions, however, can be highly skewed 
with a long right-hand tail, resulting in unreasonable mean estimates for WTP (Hensher and Greene 2003). We will therefore refer to the more robust median WTP in the following.

To illustrate the effect of selected variables, we estimate the WTP under different scenarios. In one set of scenarios, we assume the lowest level of flood risk (less frequently than once every 200 years), while in a second set, the highest level (once every 10 years). Within these two sets, we let the county's share of flood insurance claims for the flood of 2013 vary from 0 to $4 \%$. The variables whose coefficients do not vary significantly between DBI and IBI are set to their means (continuous) or modes (dummy), except for the university variable. Since the university coefficients vary nearly significantly between DBI and IBI in the MXL model (and weakly significantly in MNL), we estimate the WTP for homeowners with and without university degree.

Table 4 presents the median WTP estimates and their 95\% confidence intervals, calculated using the delta method (see e.g., Oehlert 1992; Bliemer and Rose 2013). For the first scenario, with the lowest flood risk, no university degree, and no flood insurance claims, the WTP for DBI is the highest. The point estimate is $€ 133$, with a confidence interval of $€ 83$ to $€ 182$. In other words, under this scenario, the monthly premium of an IBI would need to undercut the DBI premium by $€ 11$ to make the insurances equally attractive. As soon as we move to counties that were more affected by the 2013 flood, the WTP for DBI decreases considerably. Likewise, a homeowner who graduated from university, or who perceives his or her home to be located in the highest flood-risk area, has a lower WTP for DBI. If these factors are combined, there are even cases where the WTP for DBI is not statistically significant anymore. For example, under the highest risk scenarios, in a county where $4 \%$ of floodinsured homes filed insurance claims, the confidence intervals include zero. And the higher the county's share of insurance claims, the more competitive IBI would be in that market.

Table 4: Willingness-to-pay estimates for switching from index-based to damage-based flood insurance under different scenarios

\begin{tabular}{|c|c|c|c|c|c|}
\hline \multicolumn{3}{|c|}{ Scenario } & \multicolumn{3}{|c|}{ Median WTP (€/year) } \\
\hline Flood risk & University & Flood 2013 & Estimate & $95 \%$ Co & nterval \\
\hline$<200$ years & No & $0 \%$ & 132.8 & 83.3 & 182.2 \\
\hline$<200$ years & No & $2 \%$ & 112.7 & 66.5 & 158.8 \\
\hline$<200$ years & No & $4 \%$ & 92.5 & 43.7 & 141.4 \\
\hline$<200$ years & Yes & $0 \%$ & 106.1 & 57.5 & 154.7 \\
\hline$<200$ years & Yes & $2 \%$ & 86.0 & 40.7 & 131.4 \\
\hline$<200$ years & Yes & $4 \%$ & 65.9 & 17.7 & 114.1 \\
\hline$>10$ years & No & $0 \%$ & 82.4 & 34.3 & 130.4 \\
\hline$>10$ years & No & $2 \%$ & 62.3 & 16.5 & 108.0 \\
\hline$>10$ years & No & $4 \%$ & 42.2 & -7.3 & 91.6 \\
\hline$>10$ years & Yes & $0 \%$ & 55.7 & 3.8 & 107.6 \\
\hline$>10$ years & Yes & $2 \%$ & 35.6 & -14.2 & 85.4 \\
\hline$>10$ years & Yes & $4 \%$ & 15.5 & -37.8 & 68.8 \\
\hline
\end{tabular}

Notes: The WTP values are estimated by assuming men (woman $=0$ ), mean values for age (56 years), income $(€ 3,300)$, risk attitude (4.8), and house value (€290,000), some sort of flood protection implemented (flood protection $=1$ ) and perceived flood risk was given (don't know flood risk $=0$ ).

However, counties with higher shares of insurance claims are the exception rather than the rule. According to the GDV data, the maximum share for the 2013 flood is $12.5 \%$. But the mean share is smaller than $1 \%$, and in some $95 \%$ of the counties, $4 \%$ or less of the floodinsured filed claims. Moreover, only 1-2\% of German homes are exposed to the highest level of flood risk. Therefore, our WTP estimates under the most conservative assumptions, that is 
the lowest flood risk and share of insurance claims, are a useful benchmark for the relative superiority of DBI over IBI.

\section{SUMMARY AND CONCLUSIONS}

Flooding is a severe natural hazard, and its relevance will probably increase due to climate change in the future. In order to cushion financial losses of flood events and to generally enhance resilience against floods, policymakers in many countries try to foster private flood insurance demand. Despite those efforts, voluntary insurance demand stays relatively weak. In this regard, IBI may help. In the case of IBI, the payments are bound to previously determined weather indices or parameters, e.g. precipitation at the location of the insured. It is expected that IBI policies may be offered at lower premiums than comparable conventional insurance policies. In this case IBI could be a new option for homeowners who are currently declining the more costly conventional insurance.

In this paper, we have analyzed the demand for IBI in Germany. Our results reveal a considerable skepticism about this alternative type of insurance. Almost two thirds of the sampled homeowners have ruled out IBI as an option to insure their property against floods, regardless of its price and other terms and conditions. In a DCE, a sample of more than 1,000 homeowners who have not categorically ruled out IBI beforehand chose their preferred insurance policy. Besides a conventional (damage-based) policy and an index-based policy, participants could also opt for a no-insurance option. Controlling for many observable characteristics and allowing for correlation in unobserved factors, our econometric results confirm that, on average, German homeowners prefer DBI over IBI. Based on our preferred model, we have derived a benchmark estimate for a reduction in monthly premiums of $€ 11$ that will offset the drawback of an IBI policy and result in equal choice probabilities.

We have also examined potential differences in the determinants of demand for the two types of flood insurance. Significant differences would indicate that IBI has the potential to reach new customer segments. However, the determinants of insurance demand turn out to be very similar for DBI and IBI. We find only significant differences in terms of perceived flood risk and flood experience. Those who live in areas of the highest flood risk, both subjectively and objectively measured, seem to derive a greater utility from IBI than others.

Being the first empirical insight in IBI demand in a high-income country, these results suggest a sobering conclusion regarding the success probabilities of that novel instrument. At least in Germany, where our empirical study was carried out, private homeowners as potential clients are very reluctant to index-based insurance products. However, as flood insurance markets are characterized by strong national peculiarities (Schwarze et al. 2011), further research may approach the question in other countries. Similarly, the picture could change if one focuses on specific customer segments, such as large enterprises or public actors who need to insure large infrastructure assets. Given the relatively higher attractiveness of IBI in floodexperienced and flood-prone areas, its role may also be strengthened if climate change induces a considerable upwards trend of flood risks. But in general, the potential of indexbased insurance solutions for increasing resilience against natural hazards in high-income countries as hoped for by some policymakers still has to be proved. 


\section{References}

Akter S, Krupnik TJ, Rossi F, Khanam F. 2016. "The influence of gender and product design on farmers' preferences for weather-indexed crop insurance.” Global Environmental Change 38: 217-229.

Atreya A, Ferreira S, Kriesel W. 2013. "Forgetting the flood? An analysis of the flood risk discount over time.” Land Economics 89 (4): 577-596.

Bichard E, Kazmierczak A. 2012. "Are homeowners willing to adapt to and mitigate the effects of climate change?” Climatic Change 112 (3-4): 633-654.

Bliemer MCJ, Rose JM. 2013. "Confidence intervals of willingness-to-pay for random coefficient logit models.” Transportation Research Part B: Methodological 58: 199-214.

Bogale A. 2015. "Weather-indexed insurance: an elusive or achievable adaptation strategy to climate variability and change for smallholder farmers in Ethiopia." Climate and Development 7 (3): 246-256.

Botzen WJW, Van Den Bergh, JCJM. 2012. "Monetary valuation of insurance against flood risk under climate change.” International Economic Review 53 (3): 1005-1026.

Brouwer R, Schaafsma M. 2013. "Modelling risk adaptation and mitigation behaviour under different climate change scenarios.” Climatic Change 117: 11-29.

Browne MJ, Hoyt RE. 2000. “The demand for flood insurance: empirical evidence.” Journal of Risk and Uncertainty 20 (3): 291-306.

Browne MJ, Knoller C, Richter A. 2015. "Behavioral bias and the demand for bicycle and flood insurance.” Journal of Risk and Uncertainty 50: 141-160.

Brownstone D, Train K. 1999. "Forecasting new product penetration with flexible substitution patterns.” Journal of Econometrics 89: 109-129.

Bruhin A, Fehr-Duda H, Epper T. 2010. „Risk and rationality: uncovering heterogeneity in probability distortion.” Econometrica 78 (4): 1375-1412.

Bubeck P, Botzen WJW, Kreibich H, Aerts JCJH. 2013. „Detailed insights into the influence of flood-coping appraisals on mitigation behaviour." Global Environmental Change 23 (5): 1327-1338.

Carson RT, Louviere JJ, Anderson DA, Arabie P, Bunch DS, Hensher DA, Johnson RM, Kuhfeld WF, Steinberg D, Swait J, Timmermans H, Wiley JB. 1994. "Experimental analysis of choice.” Marketing Letters 5 (4): 351-368.

Ciscar J-C, Iglesias A, Feyen L, Szabó L, van Regemorter D, Amelung B, Nicholls R, Watkiss P, Christensen OB, Dankers R, Garrote L, Goodess CM, Hunt A, Moreno A, Richards J, Soria A. 2011. "Physical and economic consequences of climate change in Europe." Proceedings of the National Academy of Sciences of the United States of America 108 (7): 2678-83.

Cole S, Stein D, Tobacman J. 2014. "Dynamics of demand for index insurance: evidence from a long-run field experiment.” American Economic Review 104 (5): 284-290. 
Collier B, Skees J, Barnett B. 2009. "Weather index insurance and climate change: opportunities and challenges in lower income countries.” The Geneva Papers on Risk and Insurance Issues and Practice 34 (3): 401-424.

Daly AJ, Hess S, Train KE. 2012. “Assuring finite moments for willingness to pay in random coefficients models.” Transportation 39 (1): 19-31.

European Commission. 2013. Green Paper on the insurance of natural and man-made disasters. Strasbourg.

GDV. 2015. Naturgefahrenreport 2015. Berlin.

Giné X, Townsend R, Vickery J. 2008. "Patterns of rainfall insurance participation in rural India.” World Bank Economic Review 22 (3): 539-566.

Hensher DA, Greene WH. 2003. "The mixed logit model: the state of practice." Transportation 30 (2): 133-176.

Hensher DA, Rose JM, Greene WH. 2005. Applied choice analysis: a primer. Cambridge University Press, Cambridge.

Hess S, Rose JM. 2009. "Should reference alternatives in pivot design SC surveys be treated differently?” Environmental and Resource Economics 42 (3): 297-317.

Hill RV, Hoddinott J, Kumar N. 2013. “Adoption of weather-index insurance: learning from willingness to pay among a panel of households in rural Ethiopia.” Agricultural Economics 44 (4-5): 385-398.

Hirabayashi Y, Mahendran R, Koirala S, Konoshima L, Yamazaki D, Watanabe S, Kim H, Kanae S. 2013. “Global flood risk under climate change.” Nature Climate Change 3: 816821.

Hole AR. 2007. "Fitting mixed logit models by using maximum simulated likelihood." The Stata Journal 7 (3): 388-401.

IPCC. 2012. Managing the Risks of Extreme Events and Disasters to Advance Climate Change Adaptation. A Special Report of Working Groups I and II of the Intergovernmental Panel on Climate Change. In: Field CB, Barros V, Stocker TF, Qin D, Dokken DJ, Ebi KL, Mastrandrea MD, Mach KJ, Plattner G-K, Allen SK, Tignor M, Midgley PM (eds) Cambridge University Press, Cambridge New York, 582 pp.

Kousky C. 2010. "Learning from extreme events: Risk perceptions after the flood." Land Economics 86 (3): 395-422.

Kriesel W, Landry C. 2004. "Participation in the National Flood Insurance Program: an empirical analysis for coastal properties.” The Journal of Risk and Insurance 71 (3): 405-420.

Kunreuther H. 1984. "Causes of underinsurance against natural disasters." The Geneva Papers on Risk and Insurance 9 (31): 206-220.

Kunreuther H. 1996. “Mitigating disaster losses through insurance.” Journal of Risk and Uncertainty 12 (2-3): 171-187.

Landry CE, Jahan-Parvar MR. 2011. “Flood insurance coverage in the coastal zone.” Journal of Risk and Insurance 78 (2): 361-388. 
Liesivaara P, Myyrä S. 2014. Government policies in changing climate and the demand for crop insurance. MTT Agrifood Research, Helsinki.

Lindell MK, Hwang SN. 2008. "Households' perceived personal risk and responses in a multihazard environment.” Risk Analysis 28 (2): 539-56.

Miranda MJ, Farrin K. 2012. "Index insurance for developing countries.” Applied Economic Perspectives and Policy 34 (3): 391-427.

Oehlert GW. 1992. “A note on the delta method.” The American Statistician 46 (1): 27-29.

Osberghaus D. 2015. "The determinants of private flood mitigation measures in Germany Evidence from a nationwide survey.” Ecological Economics 110: 36-50.

Petrolia DR, Landry CE, Coble KH. 2013. "Risk preferences, risk perceptions, and demand for flood insurance.” Land Economics 89 (2): 227-245.

Raschky PA, Schwarze R, Schwindt M, Zahn F. 2013. „Uncertainty of governmental relief and the crowding out of flood insurance.” Environmental and Resource Economics 54: 179200.

Scarpa R, Ferrini S, Willis KG. 2005. "Performance of error component models for status-quo effects in choice experiments.” In: Scarpa R, Alberini A (eds) Applications of simulation methods in environmental and resource economics, Springer, Dordrecht.

Schwarze R, Schwindt M, Weck-Hannemann H, Raschky P, Zahn F, Wagner GG. 2011. "Natural hazard insurance in Europe: tailored responses to climate change are needed." Environmental Policy and Governance 21: 14-30.

Skees JR, Barnett BJ. 1999. "Conceptual and practical considerations for sharing catastrophic/systemic risks.” Review of Agricultural Economics 21 (2): 424-441.

Skees JR. 2008. "Innovations in index insurance for the poor in lower income countries." Agricultural and Resource Economics Review 37 (1): 1-15.

Takahashi K, Ikegami M, Sheahan M, Barrett CB. 2016. "Experimental evidence on the drivers of index-based livestock insurance demand in Southern Ethiopia." World Development 78: 324-340.

Terpstra T, Lindell MK. 2012. “Citizens' perceptions of flood hazard adjustments: an application of the protective action decision model.” Environment and Behavior 45 (8): 9931018.

Train KE. 2009. Discrete choice methods with simulation, 2nd edn. Cambridge University Press, Cambridge. 